Cómo citar este artículo en MLA: Cárcano, Enzo. “El más lejano Dios desconocido’: La indagación ontológica del poeta-médium en Visiones y Forma oculta del mundo, de María Rosa Lojo". Escritos 27. 59 (2019): 296-312. doi: http://dx.doi.org/10.18566/escr.v27n59.a05

Fecha de recepción: 03.04.2019

Fecha de aceptación: 21.05.2019

\title{
“El más lejano Dios desconocido": \\ La indagación ontológica del poeta-médium en Visiones y Forma oculta del mundo, de María Rosa Lojo
}

\author{
“The Most Distant Known God": \\ Ontological Inquiry of the Medium-Poet \\ in Maria Rosa Lojo's Visiones and Forma Oculta del Mundo \\ "O mais alheio Deus desconhecido": \\ a pesquisa ontológica da poeta-medium \\ em Visiones e Forma oculta del mundo de Maria Rosa Lojo
}

\author{
Enzo Cárcano ${ }^{1}$ []
}

1 Doctor en Letras por la Universidad del Salvador (Argentina). Consejo Nacional de Investigaciones Científicas y Técnicas, Instituto de Filología y Literaturas Hispánicas Dr. Amado Alonso, Universidad de Buenos Aires - Universidad del Salvador (Argentina). Integrandte del grupo de investigación "Los territorios comparatistas: Literaturas 


\title{
RESUMEN
}

La obra lírica de María Rosa Lojo constituye un verdadero proyecto de indagación ontológica, es decir, un modo de explorar la relación del hombre con su propio ser/ estar en el mundo y con lo trascendente. En sus primeros dos libros, Visiones (1984) y Forma oculta del mundo (1991), el hablante lírico toma la forma de un poetamédium que se asienta entre dos mundos, asume el rol de nexo con el misterio y da forma a una serie de visiones que oscilan entre el kairós de la revelación momentánea y la impotencia final, estado que signa el tono de ambas antologías.

Palabras clave: Poesía argentina; Indagación ontológica; Conocimiento poético; Lojo; Poeta-médium.

\begin{abstract}
Maria Rosa Lojo's poetic work is a true project of ontological inquiry, that is, a way of exploring the relation of humans with their own being-in-the-world and with what is transcendental. In her first two works, Visiones (1984) and Forma oculta del mundo (1991), the speaker is a medium-poet who is placed between two worlds, who plays the role of being the link to mystery, and who shapes a series of visions that swing from the kairos of momentary revelation to final helplessness, a state that characterizes the tone of both anthologies.
\end{abstract}

Key Words: Argentinian Poetry, Ontological Inquiry, Poetic Knowledge, Maria Rosa Lojo, Medium-Poet.

\section{RESUMO}

A obra lírica de Maria Rosa Lojo constitui um verdadeiro projeto de pesquisa ontológica, isto é, um modo de examinar a relação do homem com seu próprio ser/ estar no mundo e com o transcendente. Em seus primeiros livros: Visiones (1984) e Forma oculta del mundo (1991), a voz lírica tem a forma de uma poeta-médium que se situa entre dois mundos, apropria-se o papel de ligação com o mistério e produz uma série de visões que oscilam entre o kairós da revelação breve e a impotência final, estado que determina o tom das duas antologias.

Palavras chave: poesia argentina, pesquisa ontológica, conhecimento poético, Lojo, poeta-médium.

nacionales/Regiones culturales/Literaturas extranjeras/Límites. La comparación como metodología y disciplina" (directora Dra. Susana Beatriz Cella). Correo electrónico: enzo.carcano@usal.edu.ar 
"Inmóvil en el tiempo central que de Sí fluye, invulnerable a todo horror y a toda dicha, el más lejano Dios desconocido." María Rosa Lojo, "Invulnerable", Forma oculta del mundo

\section{Introducción}

$\mathrm{R}$ eunida en Bosque de ojos, la obra lírica de María Rosa Lojo, sea que se la clasifique como prosa poética o como microficción, constituye trascendente. En particular, en el universo que construye Lojo con elementos de distintas tradiciones, la lírica aparece como vehículo entre dos mundos, el sensible y el invisible-ancestral -nunca plenamente poseído, pero sí entrevisto-, como búsqueda por alcanzar una unidad perdida. Visiones, aparecido en 1984, representa el primer hito de la trayectoria poética lojiana y contiene algunas de sus claves principales. Puntualmente, como pretendo exponer en el presente trabajo, en el libro inicial la búsqueda del ser está vertebrada por la voz de un hablante lírico que aparece como poeta-médium. Este, su palabra, asume el rol de nexo con lo recóndito y da forma a las visiones, que oscilan entre el kairós de la revelación y la impotencia, fluctuación propia de ese peculiar modo de conocer que es la poesía. Forma oculta del mundo constituye, en este sentido, una continuación -o, más bien, un ahondamiento- de la exploración iniciada en el libro anterior: nuevamente la frontera -a la vez espacial y temporal- que divide el territorio de lo trascendente -inalcanzable, inefable- del impreciso aquí y ahora del tú lírico -a veces masculino, a veces femenino- que bien puede ser concebido como un desdoblamiento del hablante, ese poetamédium que da forma a la frustración -en algunas piezas matizada por un tono tímidamente auspicioso- del que, a pesar del "abandono de Dios", atisba la región otra, el más allá.

\section{Conocimiento poético}

Desde el momento de su aparición, la cuestión de la clasificación genérica de la lírica de Lojo ha sido uno de los temas más recurrentes en la crítica a ella 
dedicada (Rodríguez Francia 114-115; Noguerol Jiménez 79-82; Piña, "María Rosa Lojo"). Sus tres primeros libros - Visiones, Forma oculta del mundo (1991) y Esperan la mañana verde (1998) - se dieron a conocer como poesía (en prosa) y fueron galardonados en certámenes poéticos ${ }^{2}$, pero Bosque de ojos (2011), la antología que los agrupa -junto con un cuarto libro inédito: Historias del Cielo- reza en la tapa "Microficciones y otros textos breves". A propósito del cambio de marbete, aclara la misma autora en el epílogo de la antología:

Hasta hace unos años, hubiese englobado estos textos (y en efecto lo hice) bajo el rótulo de "poemas en prosa", aunque la "prosa" y la "dosis de poesía" que esa prosa pudiera tener siempre ofrecieran alguna incomodidad para los fanáticos de las clasificaciones. Cuando apareció la hospitalaria categoría de "mini" o "microficción", esas incertidumbres o reparos se diluyeron felizmente. (Lojo, "Bosque" 247)

Como aquí, en un par de entrevistas con Carolina Depetris ("La inexorable" 193; "Poesía, Poética" 163-164), Lojo también minimiza la necesidad de las clasificaciones tajantes, pero reconoce que existe una diferencia entre los dos libros iniciales y los dos más recientes: "Los primeros sobre todo describen y definen por vía metafórico-simbólica. Los dos últimos son más narrativos pero creo que no por eso menos poéticos" (Depetris, "Poesía, Poética" 165). Creo que esta distinción puede explicarse a partir de otra, la forma que adopta el hablante lírico en esas obras: mientras que en Visiones y Forma oculta del mundo -en los que resuenan ecos orozquianos- la enunciación aparece a cargo de lo que llamaré poeta-médium, que entrevé un plano otro cuya traducción al lenguaje le resulta angustiosamente impracticable, en buena parte de Esperan la mañana verde e Historias del Cielo, la tensión -¿lírica?- se relaja en trazos narrativo-descriptivos a cargo de un hablante -si no más seguro- menos grave, más sosegado y, por momentos, cómplice. Me interesa particularmente aquí la primera de estas modalidades, ya que constituye una manifestación singular de esa vertiente lírica -intencionadamente amplia- que he llamado

2 Visiones recibió el Primer Premio de Poesía de la Feria Internacional del Libro de Buenos Aires en su décima edición (1984), cuyo jurado estuvo conformado por Olga Orozco, Alberto Girri y José Isaacson. Forma oculta del mundo obtuvo el Primer Premio de Poesía Dr. Alfredo A. Roggiano y el Segundo Premio Municipal de Poesía de Buenos Aires. 
de indagación ontológica, y que se propone como un tipo de exploración poética de lo misterioso de la existencia humana, del ser/estar en el mundo del hombre y de su relación con lo trascendente ${ }^{3}$. Esta categoría se presenta como una altermativa actual a la más tradicional de "poesía religiosa", que acarrea el lastre de doctrinas o confesiones particulares, y cuyo empleo indiscriminado ha redundado en una plurivocidad tal que dificulta cualquier acuerdo sobre sus alcances (Cárcano, "Es que nos excede" 9-16), algo similar a lo que ocurre con la noción de "poesía mística" cuando no se la considera desde una perspectiva socio-histórica como la de Michel de Certeau en La fábula mística (cfr. Cárcano, "Con los ojos en la noche"). En esta línea, según ha observado acertadamente Cristina Piña ("Búsqueda, Frustración y Encuentro" 103-106), entre los siglos XIX y XX, con el Romanticismo alemán -en las figuras señeras de Hölderlin y Novalis-, el simbolismo francés -con Baudelaire, Rimbaud y Mallarmé, entre los más relevantes- y el surrealismo, el absoluto religioso fue sustituido por el poético, y el poeta se erigió así en un vidente capaz de llegar, con su palabra, más allá de lo cotidiano y aparente, hasta lo más recóndito y esencial. Quizá quien mejor sintetizó en sus formulaciones este viraje fue Martin Heidegger, agudo lector de los autores referidos, además del Maestro Eckhart, Angelus Silesius, Rilke, Trakl, Celan o René Char, algunos de los cuales también forman parte de las referencias de Lojo. En rigor, para el autor de Ser y tiempo, "el lenguaje es la casa del ser", y los poetas -y los pensadoresson sus guardianes (11-12), es decir, quienes pueden conseguir, en la palabra, la apertura para el acontecer del ser y, así, la existencia auténtica del hombre. La obra del filósofo alemán constituye una recuperación del pensamiento poético en contraposición a la razón moderna, epítome de la metafísica de la presencia que ha llevado al olvido de la diferencia ontológica y, por tanto, a un vivir en desacuerdo con la propia esencia humana. De este modo, confluyen en sus textos tradiciones líricas como la mística y la romántica, ambas cimentadas sobre el poder de la palabra poética, el terreno donde se emprende la búsqueda, y de la misión del poeta como buscador de las realidades últimas, del misterio.

3 Remito al número 60 de la revista Gramma, titulado Poesía Argentina de Indagación Ontológica. Este monográfico reúne textos de distintos críticos (Calle Romero, Cella, Legaz, Milone, Piña, Vera Barros, Zonana) sobre distintos poetas argentinos (Pizarnik, Gelman, Orozco, Juan L. Ortiz, Biagioni y Fijman), además de un artículo introductorio (“Es que nos excede': Modulaciones de la Poesía Argentina de Indagación Ontológica”) en el que abordo la fundamentación de la noción de "poesía de indagación ontológica". 
También para otros pensadores contemporáneos, a la poesía le cupo y le cabe aún la tarea de la indagación ontológica, allí donde no alcanzan ni la doctrina de las instituciones religiosas ni la razón científica. En su ya célebre Filosofía y poesía -en la que resuenan los postulados heideggerianos-, María Zambrano, al comparar estas dos formas de conocer, subraya el carácter a la vez iluminador y doliente de la segunda, que "sufre el martirio del conocimiento, padece por la lucidez, por la videncia" (88), porque la poesía, a diferencia de la filosofía, no busca captar lo que ya está formado ni descubrir leyes sino que es creación en el sentido más propio, es darle forma a lo que todavía no la tiene, tarea que implica necesariamente temor y angustia (88-96). Y en esa búsqueda, la poesía, también distanciándose de su par, siempre va hacia el origen: "imposible que no veamos en ella el camino de la restauración de una perdida unidad" (97). Sus palabras evocan de algún modo ese notable texto metaliterario con el que Olga Orozco quiso dar su visión del quehacer lírico, evidentemente influenciada por la tradición romántica y la surrealista: Alrededor de la creación poética, en el que la autora de Los juegos peligrosos sostiene que la poesía es un modo -siempre infructuoso en sus alcances últimos- de remontar el camino de las contingencias -de la división- hacia el principio, en el que éramos uno con la divinidad. Pero, si la poesía es una "tentativa perversa y malsana" por su irremisible destino de fracaso, cuál es, entonces, su función: "ayuda a las grandes catarsis, a mirar juntos el fondo de la noche, a vislumbrar la unidad en un mundo fragmentado por la separación y el aislamiento", concluye la escritora pampeana (473).

Como se ve, aunque de modos disímiles, tanto Zambrano como Orozco conciben la poesía como un modo especial de entrever una realidad otra, de contemplar aquello que se escapa. En una línea solidaria, el poeta español José Ángel Valente -también lector de Heidegger y de la mística española- escribe, en un breve texto titulado "Conocimiento y comunicación", que "la poesía es, antes que cualquier otra cosa, un medio de conocimiento de la realidad" (19). Pero este tipo de conocimiento es especial: a diferencia del científico, no es predictivo, no se deduce de la repetición de los fenómenos, sino que aspira a captar la experiencia humana en toda su singularidad, en su "carácter único, no legislable, esto es, lo que hay en ella de irrepetible y fugaz" (21). Y el sitio donde esto sucede es el poema, que es en sí mismo el acto de conocer: "el poeta conoce la zona de realidad sobre la que el poema se erige al darle forma poética: el acto de su expresión es el acto de su conocimiento" (22). Esto sucede, según Valente, aun en el caso de la poesía mística de, por ejemplo, San 
Juan de la Cruz, ya que la "experiencia, en cuanto susceptible de ser conocida en su particular unicidad, no existe más que en los poemas del santo" (25).

En línea con lo expresado por Zambrano, Orozco y Valente, también para Lojo -quien señala, entre sus referentes literarios, a Hölderlin, Rilke, Rimbaud, Orozco y al destacado cultor del surrealismo Enrique Molina (Depetris, "La inexorable" 198)- la poesía es búsqueda, según ella misma lo expresara en algunos textos metapoéticos dispersos. Quisiera detenerme en la conferencia "Una poética de la memoria ancestral", que la autora leyó en 2017, en un encuentro, en Paraná, Brasil. En él, y a propósito de su propia producción lírica, Lojo traza una analogía entre la labor del chamán y la del poeta por sus afinidades en tanto ambos se conectan con otras realidades ( $u$ otros planos de nuestra realidad) al operar una suerte de éxtasis: "El viaje de la poesía se ha parecido siempre, para mí, al viaje del chamán que lo lleva a las zonas de lo desconocido pero reconocido. Al corazón de la memoria ancestral". Si bien no pretendo impugnar esa apreciación, creo que la figura que adopta el hablante lírico en Visiones y Forma oculta del mundo es, más bien, la del médium que la del chamán, quizá más propia de los últimos dos libros. La razón principal, a mi juicio, radica en que ese yo que se construye en los textos que considero en el presente trabajo, aunque comparte con el chamán la capacidad de entrever lo trascendente, no puede operar sobre ello, ni sobre el plano propiamente terrenal tampoco: no tiene poderes adivinatorios, ni salvíficos, ni invocatorios. Su fuerza está en ver ese costado misterioso, en hacer de "medio" de revelación. Y su angustia es la contracara de esa potencia: la palabra no le alcanza, ve y no puede comunicar cabalmente eso Otro que se le presenta y a lo que se entrega. Esta tensión -siguiendo los postulados de Antonio Rodrigues recuperados por Gustavo Zonana (47-55) - redunda en una suerte de descentramiento del sujeto lírico, que puede advertirse, por un lado, en el desdoblamiento gramatical del poeta-médium en dos instancias: la de la voz que enuncia (yo) y la del destinatario o paciente ( $t u ́)$; y por el otro, en la fluctuación genérica del $t u ́$, a veces masculino, a veces femenino.

\section{"Dios (por decir algo, por decir nada)"}

Este sintagma, que abre el último poema de Visiones, condensa la modulación propia de indagación ontológica que vertebra todo el libro inicial de Lojo: por 
un lado, la meta, el fundamento, más intuido que efectivamente conocido, que mueve al hablante: Dios, que debe entenderse, por fuera de un sentido doctrinario u ortodoxo, como la Unidad. Por el otro, en una suerte de impugnación o matización parentética, la duda, concomitante a la indagación y fuente de angustia: esa oscilación entre "algo", es decir, una positividad imprecisa -un "no sé qué / que se alcanza por ventura", decía San Juan de la Cruz-, y "nada", la negación esencial. Esta incerteza se halla en el carácter mismo de las visiones que dan nombre y tono al poemario. Y esto, no porque se relate aquí el episodio concreto de una búsqueda frustrada o incompleta, sino porque el propio ejercicio de la palabra -de la poesía- es concebido como el espacio del indagar, como la arena en la que se da la lucha por vislumbrar lo Otro, de suyo inefable. A ello responde ese "decir a pesar de" del hablante, que, aun advertido de esa "nada" que busca, dice. En este sentido, ese hablante aparece como un poeta-médium, esto es, a medio camino entre lo Otro y la palabra; entre un olvido distante, primordial, y la memoria, polaridad, esta última, recurrente en la obra lojiana.

Visiones está estructurado en seis apartados: "Signos oscuros", "La palabra muda", "Revelaciones", "Los avatares", "De los amados", "El Dios que huye". Cada uno, encabezado por un epígrafe de un autor distinto que hace referencia al acto de ver o de conocer: san Pablo ${ }^{4}$, Carson McCullers ${ }^{5}$, Arthur Rimbaud ${ }^{6}$, Heráclito de Éfeso ${ }^{7}$, Dámaso Alonso ${ }^{8}$ y Friedrich Hölderlin'. El libro todo,

4 "Ahora vemos por espejo, oscuramente, mas entonces veremos cara a cara. Ahora conozco en parte, pero entonces conoceré como fui conocido" (Lojo, Bosque 209).

5 "Se preguntó qué música interior oiría el mudo, ya que sus oídos eran insensibles. Nadie lo sabía. ¿Y las clases de cosas que diría si pudiera hablar? Tampoco lo sabía nadie" (217).

6 "Visto bastante. La visión se ha encontrado en todos los aires./ Tenido bastante. Rumores de las ciudades, por la noche y al sol, y siempre./ Conocido bastante. Los altos de la vida. ¡Oh rumores y visiones" (223).

7 "Una misma cosa en nosotros lo vivo y lo muerto, lo despierto y lo dormido, lo joven y lo viejo: lo uno, movido de su lugar, es lo otro, y lo otro, a su lugar devuelto, lo uno" (229).

8 ¿Hacia qué hondón sombrío me convida,/ desplegada y astral, tu cabellera?/ ¡Amor, amor, principio de la muerte!" (235).

9 "Nah ist / und schwer zu fassen der Gott" (241). 
a su vez, se abre con dos citas en el mismo sentido, una de Rainer Maria Rilke $^{10}$ y otra de san Agustín ${ }^{11}$. De los ocho nombres, cinco son poetas, dos son santos y, el otro, un filósofo oracular. Todos, de algún modo, subrayan el carácter mediador, intercesor, de la palabra que escapa al corsé que impone la racionalidad moderna. Así, esos fragmentos no solo funcionan como índices paratextuales o como marcos, sino que también establecen un diálogo con los textos lojianos que va dando forma a la búsqueda lírica del hablante.

Cada una de las secciones en las que se divide el libro podría pensarse como un trance visionario de ese hablante que asume la forma de poeta-médium -desdoblado continuamente en un yo y un tú, alternativamente masculino y femenino- o, al menos, como un ensimismamiento, ya que no hay notas referenciales que den cuenta al lector de coordenadas espacio-temporales precisas, más allá de la propia actividad poético-visionaria, pura interioridad que se construye, en efecto, sobre una prosa eminentemente lírica cargada de imágenes metafóricas. Cito completo el primer poema del libro:

Con pasos de cazador nocturno, escuchando el murmullo de los astros que caen sobre las aguas quietas, con pasos de peregrino y amante en vela, con los ojos atónitos del que alcanza la orilla de otro mundo durante el sueño, así te asomas a las aguas donde el mundo se invierte, donde las formas reales del ser y del amor te miran desde balcones ya intocables, desde terrazas desamparadas y olvidadas, desde los cuartos de infancia donde la madre cantó por vez primera en el abrirse original del día, en el momento del júbilo y el tránsito. (Lojo, "Bosque" 211)

El texto está estructurado sobre el contraste entre la cautela del tú ("se asoma" "con pasos de cazador nocturno" y "escuchando el murmullo") que se acerca, en tiempo presente, "a las formas reales", distantes ("balcones ya intocables"), lejanas en el tiempo ("terrazas desamparadas y olvidadas"), afincadas en un pasado familiar ("la madre") y vital ("la infancia") desenfadado y dinámico ("el momento del júbilo y el tránsito"). No obstante los elementos concretos que

10 “Aprendo a ver. No sé por qué, todo penetra en mí profundamente, y no permanece donde, hasta ahora, todo terminaba siempre. Tengo un interior que ignoraba" (208).

11 “... intuimos con la mirada del alma la forma de nuestra existencia” (208). 
se mencionan ("balcones", "terrazas", "los cuartos") y el movimiento descrito ("asomarse"), la atmósfera del pasaje remite a la interioridad del tú propia de la visión, por la que se accede, especularmente ("las aguas donde el mundo se invierte") a esa tierra otra y distante que es el pasado. Se trata, podría pensarse, del ejercicio de la memoria.

El poeta-médium actúa entonces como tejedor de esas visiones en las que se vislumbra una realidad otra -distante, perdida- en la forma del kairós, concepto -más cualitativo que cuantitativo, subversión de lo cronológicocon el que se designa un breve instante propicio, una abertura, irrepetible y efímera, hacia otro plano. La palabra poética es la posibilidad de conocer eso Otro entrevisto fugazmente. Pero se trata de un conocimiento arduo, indirecto y, por esa misma razón, angustiante para el hablante, que se debate entre la alegría y la desesperanza: "Toda mi palabra es una gran torpeza, ducha en entrelazar visiones indecibles" (225), reza la primera pieza de "Revelaciones". Y en la cuarta de "La palabra muda" tenemos: "No es un objeto, un rostro, un nombre. Es la visión a través del objeto, del rostro, del nombre, lo reclamado [...]. vuelves con el don que tampoco es tuyo, con el lenguaje concebido en la insistencia, con ese desgraciado ballestero que nunca da en el corazón de nada" (222). Visiones inefables ("indecibles"), especulares, reflejas ("a través de"), y articuladas ("entrelazadas") en una palabra que es, al mismo tiempo, dádiva de otros ("don que tampoco es tuyo") y afán propio ("concebido en la insistencia"), pero que jamás acierta ("ballestero que nunca da en el corazón de nada").

Con todo, una nota de júbilo hallamos en la segunda composición de "Revelaciones": "He aquí la memoria de tu estirpe difusa. Te han legado la grava y el cincel y las calles ventosas en las últimas cuevas del Sur, cuyos techos son el cielo sin límite. [...]. ¡Aleluya! Has rescatado lo que no se ve. ¡Píntalo!, dicen" (226). Aparece así la memoria, ancestral o familiar, como posibilidad de ver, de conocer, que al poeta le cabe recuperar. A él le ha sido dada la palabra ("la grava y el cincel") y la naturaleza mediadora con el Todo ("cielo sin límite"). La memoria aparece en Visiones casi como un mandato ${ }^{12}$, como un deber connatural al hablante en tanto poeta: "Ayer lo viste todo y eras mudo;

12 "Mientras olvidas has matado; no puedes recuperar. Mientras recuerdas persiste lo nuevo en su inexplorada soledad" (231), sentencia el hablante en "I" ("Avatares"). 
hoy tienes habla y cuesta la visión. Vas a pagar por ella lenta paciencia, arduas metamorfosis, y serás uno: lo que devienes y lo que recuperas", se dice en el segundo poema de "Avatares" (232). Como queda dicho, a diferencia del mago o del chamán, no tiene poderes sobrenaturales: como médium, su palabra insinúa un plano etéreo que, sin embargo, no puede poseer y sobre el que no tiene poder de acción, como bien se advierte en el final de la segunda pieza de "Los amados": "... así el padre y la madre, cuyos rasgos se borran bajo la luz creciente de los párpados, se te aparecen, sin que ningún amor los pueda retener, eternos y fugaces frente a su muerte" (238). Ver, aquí, es también caer en la cuenta de lo irremisiblemente perdido ("sin que ningún amor los pueda retener"), de aquello que, alguna vez tan íntimo ("el padre y la madre"), hoy solo permanece, distante y oscuro ("cuyos rasgos se borran"), en la forma de recuerdo.

Los registros más angustiosos nacidos de la inaccesibilidad de lo Otro, del pasado, se hallan en los dos últimos poemas de la sección postrera, precisamente titulada "El Dios que huye". Allí, el hablante se muestra impotente por decir la divinidad, como se advierte en la segunda pieza:

Enciende un cirio, feligrés de la nada, enciende un cirio. Pero no hay altar donde colocar esa llama, no hay divinidad a quien ofrecer ese incendio miserable, ese crepitar de un fuego en la ceniza que arde como un lenguaje antiguo, como el olvidado Libro del Mundo, desde su ciega cavidad original, desde ti mismo. (244)

No se trata de incredulidad ni de nihilismo sino de la desorientación que genera el olvido, hecho que refuerza el mandato de recordar, de "decir a pesar de": otrora hubo un Liber Mundi, es decir, una lengua que hacía inteligible el mundo como creación de un Dios presente, pero se ha extraviado, y la divinidad se ha retraído, se ha vuelto misterio. Con todo, aunque aparezca como un acto inútil, el hablante exhorta a encender ese fuego, ese resto de una sabiduría antigua que sabía hablar de lo Otro ("ceniza que arde como un lenguaje antiguo"). Cito completo el último texto: "Dios -dices-, Dios (por decir algo, por decir nada): una palabra como una rosa importuna en la desgarradura más antigua del otoño, una palabra como un pozo insensato, una palabra que se destroza como la flor de una granada contra el sueño delicado, contra el sueño silencioso e inútil de tu garganta" (245). Aquí la palabra aparece como un sinsentido destinado a sucumbir ante la futilidad que se impone y, sin embargo, está el acto de pronunciarla; nuevamente ese "decir a pesar de" al que el poeta- 
médium está atado por naturaleza. No obstante estas notas amargas del final, como queda dicho al comienzo, la oscilación entre este sentimiento, por un lado, y el afán de esa "danza no bailada todavía que llama" (243), por otro, constituye la naturaleza misma de Visiones, verdadera indagación ontológica y lírica, conocimiento poético al decir de Valente.

\section{"Te han dicho: no retornes"}

La negativa expresada en este pasaje -el comienzo de "Fuera", antepenúltimo texto del libro- marca el final del itinerario que el hablante, desdoblado en un tú proteico que le sirve de figura catalizadora del decir, emprende en Forma oculta del mundo -título que ya expresa lo recóndito y misterioso que es el fundamento, la esencia-: ha llegado a vislumbrar un más allá del tiempo, de la muerte, un Dios esquivo y abandónico que no se deja aprehender en la palabra, y encalla en ese puerto que ya conoció en Visiones el de la angustiosa y solitaria intemperie del que se entrega a lo Otro indiferente.

Como el primer libro, el segundo también está enmarcado por un cita inaugural ${ }^{13}$ y dividido en secciones: "Magias", "Lunas", "Esperas", "Tránsitos", "Centros", "Transfiguraciones" y "Duelos". Los epígrafes que sirven de pórtico y clave de lectura para cada una de ellas, sin embargo, a diferencia del libro anterior, pertenecen casi enteramente -salvo el último- a la propia autora. Tales conjuntos, por otro lado, ya desde su título, van jalonando los hitos de una exploración que se inicia como posibilidad y acaba como impotencia. A propósito, el texto que encabeza "Magias", reza: “Todos los amaneceres la voz de los mendigos y de los mudos invade el sueño. A través de la grieta cantan los mensajeros del reino donde todo y nada sucede. Despertarás con una música que no te pertenece, una palabra que derriba los astros, un conjuro que incendia tus párpados de piedra" (139). De este modo, la sección puede leerse como el nuevo comienzo de una indagación ya emprendida ("Todos los amaneceres") que tiene lugar en un intersticio entre dos planos ("sueño",

13 Esta pertenece a "Bellos ojos”, de Héctor Álvarez Murena y reza: “iDesaparecer/ la tierra!/ Halla/ la antorcha/ de la ceguera/ .../ Como moneda de oro,/ la esfera/ entonces/ refulge" (Lojo, "Bosque" 138). 
"grieta"), uno de los cuales se revela como un sitio atópico que es pura síntesis y potencia ("todo y nada sucede"). De ese más allá llega el canto de los mensajeros, esa música, esa palabra y ese conjuro extraños y poderosos como el fuego de una visión. Pero los epígrafes del último apartado ${ }^{14}$ dan cuenta de lo que no fue, de lo infranqueable que resultó el portal hacia ese otro lado que aparecía como meta. Cabe pensar, entonces, el recorrido que va de "Magias" a "Duelos" como ese "eco" del que habla Cunqueiro, ese recuerdo tardío del haber percibido y ese saber del no poder volver atrás, pero también como la peculiar forma de indagar y conocer poéticamente que caracteriza la lírica lojiana hasta principios de los noventa.

Según se ha dicho, la sección primera del libro es el inicio del acercamiento a lo Otro, que escapa del tiempo y del espacio, y que desde ahora se presenta como una atracción peligrosa pero inexorable. Así, en "Bellezas", por ejemplo, hallamos:

Hay una forma, un pájaro detrás de la ventana, alado alud. Sin vacilar, rompes el vidrio con una furia blanca y lo abrazas a través de la sangre. Tienes miedo de mirarlo y cuando abres los ojos no lo ves. Pero las alas crecen en tu mano y se confunden con tu propio cuerpo. Ya no tienes rostro en los espejos. Alguien te ha hecho de la belleza Otra, clandestina y terrible. (142)

El pájaro, símbolo tradicionalmente asociado a las relaciones entre el cielo y la tierra (cfr. Chevalier 154 y ss.; y Rivas), surge como pura esencia ("forma" invisible a los ojos), intensa ("alado alud") e irresistible ("sin vacilar"), cuya riesgosa proximidad transforma y despersonaliza. Imágenes similares se suceden en el mismo sentido en otras piezas del primer apartado -en "Viento", por ejemplo, "tu rostro se borra, rasgo a rasgo, hacia las más remotas regiones de la luz" (144); en "Máscaras", "Ya no podrás ser lo que fuiste" (148)- y aun del segundo, "Lunas", en el que el cuerpo representa, a la vez, oportunidad y obstáculo para ir más allá: "no hay redentor que libere de la miseria del cuerpo,

14 El primero, de Álvaro Cunqueiro, dice: “...y ahora sabes/ por un eco lejano/ en qué perdiste la vida sin saber que la vida/ ya no vuelve, nunca, jamás./ La vida es tal el eco de un sueño/ que ahora sabes que lo tuviste, por un eco". El otro pertenece a Ernesto Sabato: "Porque no hay poesía festiva, alguien había dicho, pues quizá solo del tiempo y de lo irreparable puede hablar" (Lojo, "Bosque" 201). 
de la riqueza del cuerpo", reza "Hilando con los rayos de la luna" (157). "Esperas", el tercer conjunto de textos, está vertebrado por la aflicción del poeta-médium, que sabe de lo limitado de sus fuerzas, de la imposibilidad de franquear la frontera que lo separa de lo que busca y siente, y de atraparlo con el lenguaje. "Y es solamente un hueso, un hueco..." constituye un ejemplo rotundo: "Es que hay una visión y no la puedes decir, acaso porque no existen palabras para ti. La vida ríe de las palabras y juega, escéptica, con esos dados que siempre han de perder" (167). Y más adelante:

Hablas. Una por una tienes palabras que no dicen nada. [...]. Las menciones que arrojas al mundo te son devueltas; no pertenecen a él. Él es siempre el tercero: de quien se habla. Ese "de" que te envía su reflejo en esquirlas.

No hay un tema fijado, hay un constante rodear lo que se escapa. (168)

Como en Visiones, aquí hallamos la idea de la insalvable disimilitud entre lo que puede verse y lo que puede decirse, brecha sobre la que se erige la figura de ese poeta-médium -auténtico "rodeador" de lo que se escapa- que funciona en estos libros lojianos a la vez como un yo y diversos tú, siempre en estado de desengaño. Y más allá, ese él que es pura fuga, "reflejo" lejano y fragmentario; ese "nudo de la delicia" inasible que aparece en "Con tus manos hirientes", de la sección "Tránsitos": "Con tus manos que solo cortan y balbucean, tus manos a las que todo se les escapa, has querido enhebrar los días sin sueño y las noches más lúcidas y las lunas que doblegan la oscuridad" (175).

El apartado "Centros" representa la nota más auspiciosa en la búsqueda del hablante de Forma oculta del mundo, ya anunciada en el epígrafe: "Has hallado un lugar imposible..." (178), comienza. Si hasta aquí el tono general del derrotero emprendido por el poeta-médium había sido de decepción, en textos como "El coro y la campana"15, "Muerte de la memoria" o "Magnificat", la naturaleza -sucedánea del Absoluto- aparece, no escapando o resistiéndose, sino dándose incondicionadamente al hablante. Así, encontramos: "Toda la cósmica región que se te muestra en su solemne sencillez celeste y su estructura de columnas precisas" (187); "[el aire] Es el vaso sin inscripciones, la eternidad neutral en la que surges, solo vivo, como si el centro de ti mismo,

15 En la primera edición del libro, esta composición se titula “Toda la cósmica región”. 
huyente y quiero, no conociera sino albricias, comienzo" (188); "Y dices Sur y alegría y promesa" (189). Pero a "Centros" le sigue "Transfiguraciones", como si el haber hallado, el haber visto comportara una metamorfosis: "Sitiado en la pureza, tu cuerpo se ha hecho espejo y transparencia: verás" (191), reza el texto que encabeza el conjunto, y ese ver, como al principio del libro, trastoca al $y o$, lo extraña, lo descentra, según ilustran los siguientes pasajes de "Donde el viajero se despoja" y "El cuadro", respectivamente: "Quieres tu yo y no lo hay: es un incesante y complejo ramo de seres o de visiones, desmembrados y finos recuerdos de muchos mundos" (196); "Sobre la tela, ese rostro desconocido, tu rostro, heredado de un Dios que todo lo abandonó, y en tus ojos, el pájaro incesante que lo recuerda" (198). Lo que queda, al final, es la soledad y la angustia de un nuevo fracaso. Los tres textos de "Duelos" lo subrayan: "No hay palabra, no hay nombre", dice el hablante, sabedor de su derrota y de que su destino es la intemperie. No casualmente el último texto se titula "Edipo, rey", como aquel que por saber quedó ciego y desterrado: "Avanzas solo, único y uncido a ese yugo invisible [...], el más terrible de los seres creados, temblor de un remordimiento en el recuerdo de Dios, desdichado insaciable, hombre" (75). La suya, la del poeta-médium, es una tarea insensata, su voz es solo un "conjuro inútil" que nada puede con un Dios que, desde Visiones, solo huye. Pero esa palabra imperfecta es quizá, como dice Zambrano, la forma posible de ese Otro que no se deja aprehender, el único modo de conocerlo: en y por la poesía, según la formulación valentiana.

\section{A modo de conclusión}

En la primera de sus entrevistas con Carolina Depetris, María Rosa Lojo afirma: “... la poesía surge como una grieta en la percepción, una fisura en la trama compacta de los días iguales. Es una brecha, un agujero irregular en lo uniforme. Y también un desfasaje, un dislocamiento, una anomalía del enfoque" ("La inexorable" 194). En esta línea, podría decirse que, con Visiones y Forma oculta del mundo, se inaugura una particular forma de extrañar lo cotidiano en busca de una revelación imposible en el lenguaje, una trayectoria poética que se erige como verdadera búsqueda del ser, de esa alteridad irreductible que aquí todavía se llama Dios. Esta indagación por y en la palabra continuará en los sucesivos libros de Lojo, que irán trocando el tono sentencioso por uno menos 
grave, más abierto a la ironía y a la experimentación lúdica, y la atmósfera ensimismada del hablante por una más expansiva y referencial, incluso más narrativa. Con todo, en estas colecciones tempranas ya aparece un rasgo axial de la poética lojiana: la figura del poeta como médium entre dos mundos, que pone en entredicho las formas de conocer que ha impuesto la razón moderna en favor del conocimiento poético de raíces antiguas, abierto al ser, a lo Otro, a la unidad perdida, aunque su destino sea, irremediablemente -no solo porque el fracaso está asegurado sino porque no puede abandonarse la búsqueda que en él desembocará-, lo imposible.

\section{Lista de referencias}

Cárcano, Enzo. “Es que nos excede’: Modulaciones de la Poesía Argentina de Indagación Ontológica”. Gramma 60 (2018): 9-25.

Cárcano, Enzo. "Con los ojos en la noche": la poesía "mística" de Jacobo Fijman en los márgenes. Buenos Aires: Universidad del Salvador, 2019.

Certeau, Michel de. La fábula mística (siglos XVI-XVII). Trad. Laia Colell Aparicio. Madrid: Ediciones Siruela, 2006.

Chevalier, Jean, y Alain Gheerbrant. Diccionario de los símbolos. Trad. Manuel Silvar y Arturo Rodríguez. Barcelona: Herder, 1986.

Depetris, Carolina. "La inexorable tentativa de la poesía: preguntas a María Rosa Lojo". RILCE 20.2 (2004): 191-198.

Depetris, Carolina. "Poesía, Poética, Creación: Diálogo con María Rosa Lojo". Gramma 60 (2018): 163-172.

Heidegger, Martin. Carta sobre el humanismo. Trad. Helena Cortés y Arturo Leyte. Madrid: Alianza Editorial, 2006.

Lojo, María Rosa. Visiones. Buenos Aires: Exposición Feria Internacional El Libro, 1984.

Lojo, María Rosa. Forma oculta del mundo. Buenos Aires: Ediciones Último Reino, 1991.

Lojo, María Rosa. Bosque de ojos. Microficciones y otros textos breves. Buenos Aires: Sudamericana, 2011.

Lojo, M. R. (2017, noviembre 22, 23 y 24). "Una poética de la memoria ancestral". Conferencia, Evento integrado LHM 2017 - XIII Seminário Nacional de Literatura, História e Memória e IV Congresso Internacional de Pesquisa em Letras no Contexto Latino-Americano (SLHM). III Seminário Internacional e IV Congresso Nacional em Estudos da Linguagem (SNEL). III Seminário Internacional de Etnia, Diversidade e Formação. II Congresso Internacional de Leitura e Literatura Infantil 
e Juvel da Rede Paranaense de Leitura, Universidade Estadual do Oeste do Paraná, Cascavel, Paraná.

Noguerol Jiménez, Francisca. "Aguijones de luz: imagen y minificción en los textos breves de María Rosa Lojo”. Ed. Juana Alcira Arancibia, Malva E. Filer y Rosa Tezanos Pinto. María Rosa Lojo: la reunión de lejanías. Buenos Aires: Instituto Literario y Cultural Hispánico, 2007. 79-95.

Orozco, Olga. "Alrededor de la creación poética". Poesía completa. Buenos Aires: Adriana Hidalgo, 2012. 465-473.

Piña, Cristina. "María Rosa Lojo: Poema en Prosa, Microficción, Microlegendarium". Gramma 21.47 (2010): 193-195.

Piña, Cristina. "Búsqueda, Frustración y Encuentro: Poesía y Trascendencia en Olga Orozco, Amelia Biagioni y Alejandra Pizarnik”. Gramma 60 (2018): 103-125.

Rivas, Luis Heriberto. Diccionario de símbolos y figuras de la Biblia. Buenos Aires: Amico, 2012.

Rodriguez, Antonio. Le pacte lyrique. Configuration discursive et interaction affective. Liège: Pierre Mardaga éditeur, 2003.

Rodríguez Francia, Ana María. Perspectivas religiosas en la poesía argentina. Alfredo R. Bufano. Francisco L. Bernárdez. María Rosa Lojo. Buenos Aires: El Francotirador Ediciones, 1995.

Valente, José Ángel. "Conocimiento y comunicación”. Las palabras de la tribu. Barcelona: Tusquets, 1994. 19-25.

Zambrano, María. Filosofía y poesía. México: Fondo de Cultura Económica, 2006.

Zonana, Víctor Gustavo. "La conformación subjetiva en el poema: variables, niveles y perspectivas de análisis". Signo \& Seña 19 (2008): 33-66. 